\title{
Different patterns of weight bearing impact sagittal spinal balance
}

HR Weiss

\author{
From 8th International Conference on Conservative Management of Spinal Deformities and SOSORT 2011 \\ Annual Meeting \\ Barcelona, Spain. 19-21 May 2011
}

\section{Background}

A physiologic sagittal alignement of the spine with lumbar lordosis and thoracic kyphosis is the most stable position of the spine, while in patients with Idiopathic Scoliosis (IS) the sagittal profile of the spine is flattened or inversed [1,2]. It has been shown that a correction of the sagittal profile also corrects coronal plane deformity in patients with IS [1]. Therefore sagittal corrections seems to play an important role in the conservative treatment of IS. Within the ,Best Practice' PT program simple tools are used to correct scoliosis in 3D. One of these tools is the sagittal realignment of the scoliotic pattern of weight bearing. The impact different weight bearing (WB) patterns might have are subject of this investigation.

\section{Materials and methods}

13 healthy subjects (females only, age range from 18 to 45 years) have been investigated with the help of suface topography (Diers ${ }^{\circledR}$ Formetric) in two different patterns of weight bearing (WB forefoot / WB heel). Kyphosis angle, lordosis angle and the inflection point (IP) between the lordotic and the kyphotic curve have been investigated.

\section{Results}

There was a significant increase of lordosis angle $\left(49,5^{\circ}\right.$ to $\left.51,1^{\circ} ; \mathrm{p}=0,047\right)$ in $\mathrm{WB}$ forefoot. No change of kyphosis angle has been detected. IP had a tendency to slip more cranially, however this was not significant.

\section{Conclusions}

WB on the forefoot increases lordosis angle and by this stabilizes the spine. The different patterns of WB do not seem to change the angle of thoracic kyphosis.

Published: 27 January 2012

\section{References}

1. van Loon PJ, Kühbauch BA, Thunnissen FB: Forced lordosis on the thoracolumbar junction can correct coronal plane deformity in adolescents with double major curve pattern idiopathic scoliosis. Spine 2008, 33(7):797-801.

2. Weiss HR, Werkmann M: Unspecific chronic low back pain - a simple functional classification tested in a case series of patients with spinal deformities. Scoliosis 2009, 4:4.

doi:10.1186/1748-7161-7-S1-P2

Cite this article as: Weiss: Different patterns of weight bearing impact sagittal spinal balance. Scoliosis 2012 7(Suppl 1):P2.

Submit your next manuscript to BioMed Central and take full advantage of:

- Convenient online submission

- Thorough peer review

- No space constraints or color figure charges

- Immediate publication on acceptance

- Inclusion in PubMed, CAS, Scopus and Google Scholar

- Research which is freely available for redistribution 